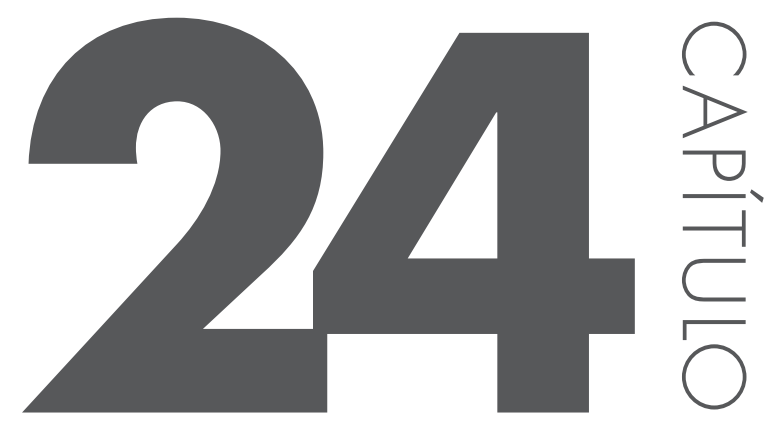

\title{
ASPECTOS DA MICROESTRUTURA DO “DICIONÁRIO DO BRASIL CENTRAL - SUBSÍDIOS À FILOLOGIA" (2009): DESCRIC̣ÃO E ANÁLISE
}

Rezende, Rayne Mesquita de ${ }^{1 *}$; Paula, Maria Helena de ${ }^{2}$

' UFG/ Regional Catalão - UAELL/ PMEL

2 UFG / Regional Catalão - UAELL/ PMEL

* email: raynemesquita@hotmail.com

\section{RESUMO}

Neste trabalho fizemos uma análise genérica da microestrutura do "Dicionário do Brasil Central - subsídios à Filologia”, de Waldomiro Bariani Ortêncio (2009), segunda edição, na versão eletrônica. Para tal, apresentamos um panorama da obra dicionarística abordando a composição de seu corpus de referência, a proposta lexicográfica, a classificação ti pológica, qu antidade de verbetes e as definições registradas, informações que julgamos indispensáveis para um estudo de teor metalexicográfico, a inda q ue, o n osso f oco s eja a organização microestrutural do dicionário. Destarte, adotamos como percurso teórico-metodológico, o aporte teórico nos principais referentes da literatura 
especializada no campo da (Meta)lexicografia, como Biderman (1984; 2001), Welker (2004), Haensch (1982), Isquerdo (2004; 2007), dentre outros autores. Concomitantemente, analisamos o "Dicionário do Brasil Central - subsídios à Filologia”, doravante DBC (2009), essencialmente na versão eletrônica. Cabe destacar que em alguns momentos recorremos à versão impressa a título de elucidação de algumas dúvidas, pois certos informes que constavam nas seções de "Apresentação" e "Apresentação à primeira edição", figuravam no dicionário apenas neste último modo. Com esse estudo, objetivamos colaborar para a ampliação do trabalho lexicográfico na esfera da variação diatópica.

Palavras-chave: Microestrutura; DBC (2009); Dicionário parcial.

Revisado pela Orientadora Maria Helena de Paula, contato: mhp.ufgcatalao@gmail.com

Rezende, Rayne Mesquita de; Paula, Maria Helena de; "ASPECTOS DA MICROESTRUTURA DO

"DICIONÁRIO DO BRASIL CENTRAL - SUBSÍDIOS À FILOLOGIA" (2009): DESCRIÇÃO E ANÁLISE", p. 421-440 . In: Seminário de Pesquisa, Pós-Graduação e Inovação da Regional Catalão (2. : 2014 : Goiás) Coletânea Interdisciplinar em Pesquisa, Pós-Graduação e Inovação - Volume 2 : Humanidades e Letras. Anais [livro eletrônico] / organizado por Adriana Freitas Neves, Idelvone Mendes Ferreira, Maria Helena de Paula, Petrus Henrique Ribeiro dos Anjos. São Paulo: Blucher, 2015. ISBN: 978-85-8039-111-4, DOI 10.5151/9788580391114-V2_Cap24 


\section{CONFIGURAC̣ÕES GERAIS DO DBC (2009)}

Sabemos que um acervo lexicográfico é composto de dois eixos, que configuram sua estrutura externa e interna, quais sejam sua macroestrutura e microestrutura. Por macroestrutura, depreendemos a extensão do dicionário, que tem como ponto de partida para sua elaboração a proposta lexicográfica - objetivo e o público-alvo para o qual se projetam os dicionários, e qual será seu "princípio linguístico” (MIRANDA, 2007 p. 263), onomasiológico ou semasiológico.

Esses fatores serão cruciais para determinação do tipo do dicionário e a seleção do corpus de referência, do qual serão extraídos os dados que integrarão a sua microestrutura. Esta, por sua vez, consiste na organização interna dos verbetes, implicando na seleção dos lemas, no tipo de definição que pode ser parafrástica, ostensiva, sinonímica entre outras, que são aplicadas consoantes às necessidades léxico-gramaticais dos lemas (BIDERMAN, 1984). Agregamse ainda ao verbete os exemplos e abonações que ilustram as formas de uso plausíveis para o definiendum em questão.

Neste sentido, segundo Unes (2009), na seção de apresentação do dicionário, que consta somente no modo impresso, o Dicionário do Brasil Central (2009), tem como proposta ser para além de uma obra de consulta, uma fonte de informações culturais abrangendo, desde lendas a descrições de festas e atividades socioeconômicas do Brasil Central.

Percebemos, na suprarreferida afirmação, duas incongruências acerca do entendimento do que vem a ser a real função do dicionário, dignas de comentário; primeiramente, um dicionário, ao fazer o registro de uma determinada parcela de unidades lexicais e seus significados, já se constitui por excelência como uma obra digna de leitura: ademais, é mais que um simples tira-dúvidas, afinal, “[...] os dicionários recolhem o tesouro lexical da língua num dado momento da história de um grupo social” (BIDERMAN, 2001, p. 132).

Já a segunda, diz respeito à falta de clareza em relação a um dicionário de língua e uma enciclopédia. Segundo Rey-Debove (1984, p. 64, grifos da autora), "o dicionário de língua é um dicionário geral que nos fala do conjunto de palavras de uma língua e que dá a definição delas”, enquanto "a enciclopédia é também um dicionário geral, mas que nos fala do conjunto das coisas duma civilização e que dá a definição delas [...]”.

Sendo assim, a função de ambos os acervos lexicográficos é o que os difere; o primeiro registra informações das unidades lexicais, selecionadas conforme um recorte adequado à proposta do dicionário no âmbito estrutural da língua (informações de ordem lexical, gramatical, semântica e discursiva), o segundo registra informações relacionadas ao extralinguístico. 
Graças ao caráter heterogêneo do léxico e sua ligação estreita com os fatores socioculturais, decorrem as variações lexicais (de designações para um mesmo conceito) que, de acordo com as variações normativas possíveis dentro de um sistema linguístico, podem ser diatópicas, diastráticas, diafásicas, diagenéricas, diatécnicas, diacrônicas dentre outras. Essas variações são motivadas por fatores exteriores ao diassistema língua, sendo perceptíveis conforme a fração que se proponha a observar.

A seleção dessas variações no nível lexical, para o registro lexicográfico, resultará em uma obra como o DBC (2009), em que, segundo seu autor, foi realizado um recorte das unidades lexicais utilizadas especificamente no Brasil Central. Assim, classificamos topologicamente o DBC (2009) como um dicionário parcial diatópico/ de regionalismos (HAENSCH, 1982, apud SILVA, 2007);

Remontando ao exposto na seção de apresentação da segunda edição obra, que data do ano de 2009, no que tange à sua macroestrutura, o banco de dados que constitui o corpus do DBC (2009) é composto por materiais oral e escrito (textos de gêneros variados: literários, jornalísticos e etc.), abrangendo um recorte sincrônico de 200 anos de referências do linguajar do Centro-Oeste brasileiro. Registra cerca de 9 mil verbetes e aproximadamente 20 mil definições (UNES, 2009).

Conquanto não seja o enfoque principal deste estudo, algo que não passa despercebido é o critério utilizado por Ortêncio (2009) e sua equipe de lexicógrafos para a delimitação do que este denomina de Brasil Central. Sobrevêm algumas dissonâncias, uma vez que, ao mencionar as localidades pretensamente recobertas pelo DBC (2009), detectamos a presença de regiões que, na divisão geográfica das unidades federativas brasileiras, não integram o Centro-Oeste (Triângulo Mineiro, Oeste baiano e Tocantins).

De acordo com Isquerdo (2007), são quesitos teórico-metodológicos indispensáveis para a produção de dicionários de regionalismos: (i) os objetivos do dicionário; (ii) a área a ser coberta e o recorte do vocabulário que integrará a obra; (iii) as modalidades da língua a serem consideradas; (iv) o estágio da história da língua a ser contemplado; (v) a abrangência e a representatividade dos regionalismos; (vi) a natureza das fontes; (vii) a teoria linguística que respaldará a elaboração do dicionário - conceito de unidade léxica e de regionalismo, estabelecimento da nomenclatura (corpus informatizado para extração e seleção das entradas) e a definição da estrutura e do tratamento dos verbetes.

Frente ao exposto sobre as características gerais do DBC (2009), percebemos que o seu resultado enquanto objeto lexicográfico deixa a desejar, 
principalmente no que se refere à área abrangida pelo dicionário e o recorte do vocabulário realizado. Além disso, não deixa claro se houve o respaldo de alguma teoria linguística para seu feitio.

$\mathrm{Na}$ seção seguinte, adentraremos para nossa temática cardeal; discorrer sobre a organização microestrutural do DBC (2009), conforme o que é postulado pela ciência lexicográfica para a confecção desse tipo de objeto.

\section{A MICROESTRUTURA DO DBC (2009): CARACTERÍSTICAS DE SUA FORMA E CONTEÚDO}

Visto que delimitamos anteriormente o conceito de microestrutura (estrutura interna dos dicionários/ organização dos verbetes), iniciamos pelo que Murakawa (2007, p. 238) apresenta como um modelo clássico de verbete;

Considera-se que o verbete ou artigo lexicográfico é a unidade mínima na organização de um dicionário. Está constituído pela palavra-entrada ou lema, que é a unidade léxica a ser tratada e por um conjunto de informações sobre essa unidade. Este conjunto, por sua vez, pode variar de acordo com o propósito do dicionário e com o público a que se destina. Reúnem-se no verbete, informações sobre etimologia, pronúncia, ortografia, classe gramatical, restrições de uso (se a palavra está em uso, se é empregada em determinada região geográfica, se é de área de especialidade, ou se está restrita a um determinado registro linguístico), sinônimos, antônimos, combinações léxicas, aspectos sintáticos relevantes, irregularidades morfológicas e principalmente a definição das diversas acepções e exemplos (grifos nossos).

Do mesmo modo que para a composição da macroestrutura dos dicionários segue-se um paradigma base tanto para as obras de natureza geral quanto parcial, tendo em vista que a presença de alguns elementos é que caracterizam uma obra como um determinado tipo de instrumento lexicográfico, com a microestrutura não será diferente.

Em consonância com Murakawa (2007), compreendemos que um verbete organizado para um dicionário do tipo parcial não terá necessariamente a mesma disposição do que um que se destina a integrar um dicionário geral. Verificamos essa afirmação, também em razão das observações realizadas no DBC (2009) essencialmente na versão eletrônica. 
Para a avaliação da microestrutura do DBC (2009) seguimos os elementos que, segundo Murakawa (2007), devem fazer parte de um artigo lexicográfico, porém, sempre atentando-nos para o fato de que se trata de uma obra que tem como foco o registro de um recorte regional do léxico. Sendo assim, os aspectos selecionados para a análise foram o lema, a categorização léxico-gramatical, modelo de acepção, abonações e exemplos.

Adotamos apenas esses cinco parâmetros para o exame dos verbetes, com base no que Frubel e Isquerdo (2004, p. 157) apresentam com componentes de um glossário de regionalismos: "entrada [obrigatória]; referências gramaticais [obrigatória]; definição [obrigatória]; sigla [obrigatória]; abonação [obrigatória]; sinônimos [opcionais]; variantes [opcionais] e remissivas [opcionais]".

Levamos também em conta o fato de que, para um verbete de dicionário parcial, essas são as informações mais relevantes, pois esse conjunto é capaz de situar e definir os itens lexicais dentro e fora do sistema língua, ao explicitar o que são e para que servem os referentes e seus conceitos designados por meio dos nomes.

Apesar de existir uma diferença entre glossário e dicionário, tomamos a composição de um glossário de regionalismos como referência para esta investigação por dois motivos: (i) devido à carência de uma obra similar ao DBC (2009), porquanto não temos conhecimento de um dicionário que enseje registrar a variação diatópica do Brasil Central; (ii) devido ao fato de que, mesmo sendo produtos diferentes da atividade lexicográfica, os dois têm em comum as propostas de registro de lexias em um contexto regional de uso, que os aproxima.

Feitas as considerações a respeito das opções teórico-metodológicas que nortearam este estudo, passamos para os dados acerca da organização dos verbetes que Ortêncio (2009) disponibiliza na seção "Guia ao leitor", que se divide em três tópicos: "1. Estrutura do verbete"; "2. Abreviaturas"; "3. Ortografia e sinais diacríticos”, os quais se segmentam em subtópicos contendo os esclarecimentos inerentes aos seus respectivos títulos.

Descrevemos cada uma das três seções citadas com uma estrutura semelhante ao que está disposto no DBC (2009), no entanto, já estão acrescidos elementos provenientes da nossa análise. Sendo o primeiro tópico o que traz os informes que mais interessam a esta proposta de investigação, esse será abordado em pormenores, a saber; 


\subsection{ESTRUTURA DO VERBETE}

a) Título: corresponde na terminologia lexicográfica aos lemas a serem definidos;

b) Iniciais maiúsculas ou minúsculas do verbete: distingue os lemas entre nomes próprios grafados em maiúsculas (caso dos topônimos e nomes de festividades) dos comuns em letra minúscula;

c) Definição: indica a maneira como figuram as definições dentro do verbete, que tem início com letra maiúscula e em alguns casos será demarcada por numeração quando o verbete tiver mais de uma definição;

d) Autoria da definição: informa que Ortêncio (2009) é o responsável pela elaboração da maioria das definições, mas que em alguns casos as definições são retiradas de outros autores;

e) Abonação dos verbetes: explicita a função das abonações, que é de apontar os contextos possíveis de uso, salientando que as abonações vêm sempre no corpo do texto em fonte menor, quando elaboradas pelo editor ou o autor, e entre aspas quando retiradas de outros autores. Notamos neste caso uma confusão entre exemplo e abonação, que explicaremos mais adiante.

f) Abonações extraídas de publicação: salienta novamente que as abonações extraídas de outras publicações virão em fonte menor, acompanhadas da identificação de autoria abreviada, além de fonte de onde foram extraídas;

g) Verbetes sem definição: são verbetes que não têm uma acepção, pois se julgou que apenas a abonação seria suficiente para clarear o significado da unidade lexical;

h) Verbetes sem abonação: são aqueles que possuem somente a definição;

i) Compostos ou derivados dos verbetes: são, por vezes, expressões idiomáticas, ditos populares ou colocações que constituem uma espécie de subentrada do verbete, sendo demarcadas por este símbolo $\bullet$;

j) Municípios, gentílicos e regiões: no caso dos municípios, as informações variam: são transpostas a unidade da federação a que pertencem, o gentílico, em alguns casos o nome dos fundadores, informações toponímicas (o que motivou o nome do local), e a data que demarca o início de seu povoamento. Convém ressaltar que entre os municípios estão registrados apenas os que fazem parte dos estados de Goiás e Tocantins, sendo deixados à parte os de Mato Grosso, Mato Grosso do Sul e Distrito Federal.

k) Informações adicionais: são dados que "extrapolam as simples definições” (ORTÊNCIO, 2009, p. 13). Seu registro é demarcado por um símbolo semelhante a uma pequena folha. São na verdade alguns exemplos e abonações na forma de expressões idiomáticas, entre outras práticas culturais populares. 


\subsection{ABREVIATURAS}

Aqui, estão dispostas as formas abreviadas das informações complementares do dicionário. A primeira listada pelo autor é a sigla Inf., que é a redução de Informante, o que sinaliza que a definição do verbete foi elaborada com base em depoimento oral. Em seguida, M.q., para Mesmo que, usada sempre nos casos de palavras com o mesmo significado e grafia diferente.

Por fim, V. forma reduzida de Ver, para fazer remissão a outros verbetes. No DBC (2009), o processo de remissão pode ser por duas causas: ausência de definição e relação semântica entre a definição e a abonação dos verbetes;

\subsection{ORTOGRAFIA E SINAIS DIACRÍTICOS}

Neste segmento, o autor discorre sobre as normas editoriais adotadas na confecção do DBC (2009), reiterando que, nessa edição, os verbetes seguem o novo acordo ortográfico, mas que foi feita a opção de apresentar a marcação de pronúncia das vogais, que logo em seguida da entrada aparecem sinalizadas entre parênteses com os respectivos acentos. Veja-se;

desmilinguido (ü) 1 Acabado; enfraquecido. 2 Chorão: "Não, aí qualquer desmilingüido tentaria pisar por cima dele, que já não tinha mais autoridade." E. Brasiliense, IN, 60 (ORTÊNCIO, 2009).

eta (ê) Exprime admiração, satisfação: Eta, sujeito bom! "Êta, Lobato macho!" A. Barbosa, MOLC, 87 (ORTÊNCIO, 2009).

Não se trata aqui da transcrição fonética, que seria o mais adequado, haja vista que, em termos de sonoridade da língua, o Alfabeto Fonético Internacional (IPA) é que faz essa representação.

Quanto às abonações, estas mantêm a ortografia da publicação original (primeira edição do DBC de 1983), tendo sido corrigidas somente as que continham erros de editoração. As que apresentam uma variação ortográfica, em relação às normas seguidas pelo DBC (2009), são acompanhadas da expressão sic, entre colchetes, como se observa na variação do lema erva, que em uma de suas abonações é grafada como herva [sic] (ORTÊNCIO, 2009).

De acordo com as observações realizadas no DBC (2009), e frente ao exposto na seção "Guia do leitor”, iniciamos a análise de sua microestrutura abordando a nominata empregada por Ortêncio (2009) para designar cada uma das partes que totalizam um verbete. 
Percebemos, por meio das descrições das estruturas dos verbetes, a sucessão de discrepâncias entre as denominações utilizadas por Ortêncio (2009) e a terminologia empregada pela ciência lexicográfica para designar os elementos integrantes de um verbete, bem como, em relação ao seu tipo de definição.

Fica visível nossa constatação quando ao referir-se à entrada do verbete, o autor a denomina de título. Esta nominata é bastante incomum, tanto que nas principais obras de referência do campo da Lexicografia e Metalexicografia, produzidas por autores consagrados como Biderman (1984; 2001), ReyDebove (1984), Borba (2003), Haesnch (1992) etc., jamais encontramos o termo "título" como sinônimo de lema, entrada/palavra-entrada.

Seguindo a mesma linha do que podemos chamar de certa "confusão terminológica", notamos a ausência da distinção entre exemplos e abonações. Embora nem todos os teóricos da Metalexicografia façam rigorosamente essa separação, como por exemplo, Rey-Debove (1984), que fala apenas em exemplos, inferimos que a distinção entre os dois é mais esclarecedora para os estudiosos da área e também para os consulentes do dicionário.

Desse modo, o que está delimitado como abonação na seção (e) abonação dos verbetes, deveria trazer informações apenas sobre as abonações, e, na seção (f) - abonações extraídas de publicação, o termo mais adequado, seria exemplo. A diferença básica entre esses dois componentes é que os exemplos são elaborados pelo próprio lexicógrafo, a fim de colaborar para a compreensão do significado. As abonações são citações de outros autores retiradas corpus que serviu de parâmetro para montagem dos verbetes. Sua função, além de exemplificar o contexto de uso, é também a de atestar a ocorrência lema (COELHO, 2008).

Em relação ao que o autor denomina de (i) - compostos ou derivados dos verbetes, de acordo com a disposição em que figuram no DBC (2009), constatamos que se tratam de subentradas, nas quais o lema compõe em conjunto com outras unidades lexicais, uma unidade fraseológica (expressões idiomáticas e colocações). Esta explanação pode ser atestada com a observação dos verbetes "menos" e "Luzia", transcritos no Quadro I exatamente como estão registrados no DBC (2009).

Após a discussão sobre as incoerências terminológicas presentes no DBC (2009), iniciamos a verificação de que tipos de unidades lexicais assumem o papel de lema nos verbetes, cuja observação de alguns destes, retirados do DCB (2009) versão eletrônica, ilustrará as colocações feitas et seq: 
Quadrol - Verbetes retirados do "Dicionário do Brasil Central - subsídios à Filologia" versão eletrônica, edição 2009. DICIONÁRIO DO BRASIL CENTRAL (2009) - VERBETES

\begin{tabular}{|c|c|}
\hline LEMA & DEFINIĈ̣̃O \\
\hline assada & $\begin{array}{l}\text { "... outros preferiam assada, isto é aguardente } \\
\text { queimada..." B. Guimarães, ERM, } 39 .\end{array}$ \\
\hline Axixá do Tocantins & $\begin{array}{l}\text { Município tocantinense. Gentílico: axixaense. Toponímia: } \\
\text { em alusão à árvore xixá, abundante na regiãa. Início do } \\
\text { povoamento: } 1957-1958 \text {. Fundadores: Bernardino Pereira Costa } \\
\text { e João Marinho dos Santos. Primeiro nome: Axixá de Goiás. }\end{array}$ \\
\hline corvjão-de -orelha & $\begin{array}{l}\text { Variedade de corvija: "... assuntando bulha no mato, } \\
\text { e um corujão-de-orelha assenta aí perto, despeja sua } \\
\text { gaita lobrega." C. Bernardes, OP, 21.2.1971. b }\end{array}$ \\
\hline devo-e-pagarei & $\begin{array}{l}\text { Nota promissória: "Naquele dia Beniamim levou dois contos e } \\
\text { quinhentos, sem devo-e-pagarei." J0, mar. 1958. "No fiado } \\
\text { valia um documento assinado pelo comprador, que áá trazia } \\
\text { impresso o texto. Era o devo e pagarei..." J. Rosa, PEGA, } 16 .\end{array}$ \\
\hline diz-que-diz & $\begin{array}{l}\text { Fuxico; boato: "E a ansiedade, a agitaccão, o corre-corre, } \\
\text { o diz-que-diz crescia na proporcão gue a festa chegava ao } \\
\text { fim." B. Elis, CIN, 26.10.1970. "0 diz-gue-diz cresceu } \\
\text { tanto que Carvalho mandou chamar..." B. Elis, OT, } 56 \text {. }\end{array}$ \\
\hline Luzia & $\begin{array}{l}\text { - aquilo que a Luzia leva na horta As fezes: ".. } \\
\text { sujeitos canalhas que fazem conta até daquilo que a luzia } \\
\text { larga atrás da horta." C. Bernardes, R, 185. "0 bobo } \\
\text { aqui, que não entendeu nada, pergunta: que vantagem } \\
\text { Maria leva nisso, gente? Somente o que a luzia levou na } \\
\text { horta, pô, porque o armazenador passou a pagar mais e } 0 \\
\text { braçagista a ganhar menos." A. Ramos, OP, 3.9.1976. }\end{array}$ \\
\hline menos & • pedir um menos. Pedir abatimento de prec̦o; pechinchar. \\
\hline Rio Verde & $\begin{array}{l}\text { Município goiano. Gentílico: rio-verdense. Início do } \\
\text { povoamento: 1835. Fundadores: Florentina Cláudia } \\
\text { de São Bernardo, Joũo Prata e José Prata. Primeiros } \\
\text { nomes: Abóboras e Dores do Rio Verde. }\end{array}$ \\
\hline trabucar & $\begin{array}{l}1 \text { Manejar trabuco. } 2 \text { Trabalhar muito para viver; labutar; } \\
\text { agitar: "E mais para dar na vista da menina do que } \\
\text { mesmo para servir, vivia eu trabucando pelos campos, } \\
\text { dando duro no curral..." E. Macedo, CON, } 43 \text {. }\end{array}$ \\
\hline
\end{tabular}

Verificamos que afiguram como lemas no DBC (2009) lexias simples, lexias complexas, unidades fraseológicas/fraseologismos, expressões idiomáticas/idiomatismos, colocações, além de elementos onomásticos (antropônimos e topônimos).

Iniciamos tratando da presença dos itens onomásticos na obra. Sabemos que na esfera da produção lexicográfica, principalmente no que 
tange aos dicionários gerais, a inserção de topônimos consiste em um tema que divide opiniões; alguns teóricos admitem que após uma delimitação criteriosa dos tipos de topônimos não existe impedimento para que sejam também entradas de dicionários (CARVALHINHOS, 2011).

Em contrapartida, outros teóricos como Coelho (2008) e Henriques (2011) discordam da interposição de topônimos nos dicionários gerais. O último defende que elementos da onomástica devem ser colocados em dicionários especiais, enquanto que o primeiro concebe presença dos nomes de lugares em dicionários como enciclopedismo, visto que não é da alçada dos dicionários, registros de informações fora do que é estritamente linguístico.

No campo dos dicionários de regionalismos, que de certa forma seguem as regras para a produção de objetos lexicográficos gerais, embora com as suas especificidades, não temos notícia de nenhuma ressalva, bem como de nenhum critério de exigência de sua introdução.

Em concordância à investigação realizada na microestrutura do DBC (2009), e diante dos estudos realizados acerca da problemática da introdução de topônimos nos instrumentos lexicográficos, inferimos que a forma mais conveniente para a colocação dos designativos dos locus seria a sua introdução no dicionário, em forma de apêndice organizado alfabeticamente com orientação semasiológica. Assim, essas informações complementam sem desorganizar a microestrutura dos dicionários, ou deixar margem de dúvida no momento de seu registro.

Sobre a ocorrência de antropônimos, como o verbete Luzia no DBC (2009), depreendemos que esta seja totalmente dispensável. Carvalhinhos (2011) assevera que não é viável a sua inclusão nos dicionários, porque estes sofrem diversos processos de adaptação (estrangeirismos, criações neológicas), que por serem constantes não são passíveis de serem sistematizados para a composição de um corpus de referência.

Ademais, não é o nome Luzia que é definido, posto que este faz parte se um sintagma maior, que forma uma subentrada sendo apresentadas para esta as acepções. Destarte, os antropônimos só devem ser incluídos nos dicionários quando surge a partir deles um neologismo que é incorporado ao léxico. Mesmo que essa concepção seja para dicionários de natureza geral, aplica-se também ao parcial/regional, porque inventariar nomes próprios não é atribuição de nenhum desses dois tipos de instrumentos lexicográficos.

Sobre a classificação do que Ortêncio (2009) chama de "título", mas que na terminologia da ciência lexicográfica denominamos de lema 
ou entrada, defrontamo-nos ao longo da nomenclatura do DBC (2009) com diferentes tipos de entrada, embora sua grande maioria seja de lexias simples. Para a discriminação das lexias, consideramos:

\begin{abstract}
Assim, no plano da língua, o termo lexema refere a unidade abstrata do léxico. As manifestações discursivas dos lexemas devem ser referidas tecnicamente como lexias. Por sua vez, as lexias se repartem em duas categorias: as lexias simples, graficamente constituídas de uma sequência gráfica separada por dois brancos [...] e lexias complexas, formadas por várias unidades separadas por brancos e não ligadas por hífen [...]. E chamaremos de lexias compostas aquelas que são ligadas por hífen [...] (BIDERMAN, 1999, p. 89, grifos da autora).
\end{abstract}

Retomamos aqui, uma discussão do que sempre representa um problema na composição dos verbetes: que critérios utilizar no momento de seleção dos lemas? Não é novidade dizer que a escrita ortográfica está longe de ser a representação do discurso verbal, em sentido lato de realização da concreta da língua, (nas modalidades oral e escrita) consonante as possibilidades combinatórias abstratas disponíveis em seu léxico e gramática.

Por esse motivo, ao registrar as entradas no dicionário geral ou parcial, há que se levar em conta os aspectos lexicais e gramaticais, já que “o dicionário é considerado como paradigma linguístico dos usos e sentidos das palavras e expressões de um idioma” (KRIEGER, 2006, p. 165).

Se essa demanda já é por demasiado intrincada nos dicionários gerais, a dificuldade de seleção é com certeza maior nos parciais. Certos usos e expressões, que fogem às regras da norma padrão da língua justamente por fazerem parte de uma subnorma. Logo, por representarem as peculiaridades culturais refletidas no léxico duma região com tamanha recorrência, não podem ter seu registro excluso do acervo lexicográfico que tenha como intento inventariar esses regionalismos.

De acordo com Biderman (1999), ao determinar os lemas de um verbete, que não sejam lexias simples, faz-se imprescindível constatar se a lexia complexa ou sintagma já foram lexicalizados, pois só assim poderá figurar com uma entrada independente, afinal seu significado como um todo já foi cristalizado na memória dos falantes. Para isso, as sequências não podem variar nem serem substituídas por sinônimos.

Tomando como base, ainda, o que propõe a supracitada autora (2001, p. 140), ao destacar que há uma grande dificuldade na categorização de 
unidades lexicais complexas de vocabulários especializados, julgamos que essa dificuldade se estende também aos dicionários de caráter parcial.

Diante disso, no DBC (2009) temos como exemplo a entrada devoe-pagarei, sinônimo utilizado para nota promissória, que inferiu-nos uma quantidade de interrogações: as unidades que a compõe têm uma coesão interna (BIDERMAN, 1999) suficiente, não podendo ser alteradas, sem que se perca o seu significado? Seria mais adequado que aparecesse como uma expressão idiomática ou colocação ao final do verbete nota? Tratase de uma lexia complexa ou de um subtipo de unidade fraseológica/ fraseologismo?

Segundo Glenk (2011), a fraseologia abrange diversos tipos de combinações de unidades lexicais, como colocações, expressões idiomáticas/idiomatismos, fórmulas discursivas de rotina, provérbios, cuja principal característica reside em serem combinações que não permitem muitas modificações. De acordo com o grau de fixidez é que distinguiremos as expressões idiomáticas das colocações.

Os idiomatismos não possuem equivalentes em outra língua, não podendo, portanto, ser literalmente traduzidos. Apresentam um grau de fixidez maior do que o das colocações, pois a sequência e as unidades que compõe uma expressão não podem ser alteradas em sua ordem e conteúdo.

Já as colocações "são combinações lexicais correntes arbitrárias, em geral não idiomáticas, cujos constituintes são contextualmente restritos" (TAGNIN, 2011, p. 87). Assim, as colocações, apresentam um grau de fixidez menor do que o dos idiomatismos, mas ocorrem com uma frequência maior do que uma combinação aleatória. Elas são formadas em geral por dois elementos: a base e o colocado, podendo esse último, ser alterado conforme o que quer expressar o falante.

Diante dos traços distintivos mencionados, podemos classificar, e ntão, devo-e-pagarei como uma expressão idiomática, posto que aparentemente seus caracteres léxico-gramaticais basilares não podem ter comutada nenhuma das suas unidades. Neste sentido, classificamos também como u ma expressão idiomática para designar fofoca ou boato a sequência diz-que-diz, pois esta apresenta em sua configuração traços de disposição lexical e sintática semelhantes aos da expressão devo-e-pagarei.

No que tange à unidade corujão-de-orelha, nome de uma variedade de coruja, a classificação será diferente. Isso porque essa unidade não equivale uma fórmula discursiva, e sim a uma designação. Então, corujão-de-orelha consiste em uma lexia composta por uma sequência de unidades lexicais que formam uma lexia (lexema em uso no discurso) separada por hífen (BIDERMAN, 1999). 
Quanto às colocações, notamos que a maior parcela de sua recorrência se dá nas subentradas. Tomamos como exemplo o verbete Luzia, em que a acepção apresentada não é a do lema. Assim, em aquilo que a Luzia leva na horta, o nome Luzia pode ser substituído por outro sem que se perca sua carga semântica, uma vez que o elemento principal dessa sequência não nos parece ser o antropônimo. A carga semântica essencial está na ação de levar algo que não pode ser claramente dito até horta, que, no referido contexto, remete à ideia de depositar ou jogar fora discretamente.

O próximo elemento de análise foi a investigação acerca da classificação léxico-gramatical dos verbetes. Ao longo de nossa observação, percebemos que nenhum dos verbetes recebe categorização gramatical, o que entendemos como uma lacuna, afinal, tanto para a composição de um verbete no dicionário geral como no parcial, a inclusão da classe gramatical do lema tem como finalidade orientar qual a função exercida pela unidade a ser definida no eixo paradigmático da língua (neste caso, especialmente nos níveis morfológico e sintático).

Passando para a ordem das acepções, detectamos certa assistematicidade em relação a esse ponto, que pode se verificado com os verbetes extraídos doo DBC (2009), transcritos no Quadro 1. Compreendemos que em termos de definição cada tipo de lema pedirá uma das tipologias definicionais, que podem ser de ordem parafrástica, ostensiva ou sinonímica.

De acordo com Biderman (1984), a definição parafrástica será em grande parte dos casos a mais eficaz, pois, ao fazer uma exposição gradual, partindo do arquilexema, que é o conjunto de traços semânticos comuns a diversas unidades para suas acepções específicas, numa relação hiperônimohipônimo, o consulente entenderá com mais facilidade o significado da unidade lexical.

Por sua vez, a definição ostensiva consiste em uma descrição em que são apontados alguns referentes, que contenham traços do item definido, para que o consulente possa fazer a associação entre o significado do definiendum e outro elemento que tenha essa característica.

A definição sinonímica deve ser evitada, porque leva a remissividade. Colocar como acepção uma unidade lexical que seja sinônima do termo definido não é descrever/explicar, mas apenas apresentar mais uma forma disponível no léxico para designar o mesmo referente e seu conceito. No quadro abaixo, seguem alguns verbetes para a exemplificação de cada classe de definição: 


\section{Quadro 2 - Verbetes retirados do "Dicionário do Brasil Central - subsídios à Filologia" versão eletrônica, edição 2009.}

DICIONÁRIO DO BRASIL CENTRAL (2009)

\begin{tabular}{|c|c|}
\hline VERBETES & TIPO DE DEFINIĈ̣̃O \\
\hline carda - V. tear (2); tecelagem. & sinonímica \\
\hline $\begin{array}{l}\text { embandeirar - } 1 \text { Fazer bandeiras de milho na roca. } 2 \\
\text { Acompanhar alguém: "O Vico era um cidadão pouco' falado } \\
\text { no lugar, vivia mesmo era embandeirado com uns homens } \\
\text { que diziam ser fiscais de banco." C. Bernardes, REC, } 59 .\end{array}$ & parafrástica \\
\hline $\begin{array}{l}\text { pedrês - Diz-se de cavalo ou mulo branco pintado } \\
\text { de preto: "Costumava cavalgar uma égua pampa e } \\
\text { puxava, pelo cabresto de corda, o seu burrico pedrês, } \\
\text { com as bruacas no lombo." O. Marques, JO, ago. } \\
\text { 1957. "Aqui a gente se conhece é como cavalo: alazão, } \\
\text { pedrês, baio, ruço, e suíço." I. Oliveira, DSO, 180. }\end{array}$ & ostensiva \\
\hline
\end{tabular}

No que concerne ao DBC (2009), comumente a outros dicionários, detectamos os três tipos de definições apontadas acima. Todavia, o que nos chamou muita atenção, tendo já sido discutido anteriormente em outros trabalhos em que nos referimos a este acervo, é o fato de alguns verbetes não apresentarem definição, não obstante somente são abonados ou exemplificados.

A ausência de uma acepção compromete utilidade principal do dicionário, que é a de elucidar os significados desconhecidos, especialmente neste contexto, por serem usos restritos a uma variação regional. No DBC (2009), os exemplos e abonações não são componentes fixos em todos os artigos lexicográficos. Figuram como substituição das acepções, ou a título de explicação para melhor compreensão das suas formas de uso, além de atestar sua recorrência na língua.

\section{CONSIDERAC̣ÕES FINAIS}

Durante o período que nos dedicamos à investigação acerca da organização microestrutural do DBC (2990), constatamos que fazer a análise de uma obra dicionarística pronta revela-se uma tarefa árdua, que exige atenção e ponderação, no que diz respeito às afirmações feitas sobre a sua configuração.

Logo, destacamos aqui nosso reconhecimento ao pioneirismo e univocidade de Waldomiro Baiani Ortêncio e sua equipe pela produção de um acervo lexicográfico como o DBC (2009), que conquanto apresente significativas incongruências tem como mérito ser o primeiro e o único dicionário conhecido a registrar os usos lexicais no Brasil Central. 
Enfim, depreendemos que nossa proposta de fazer uma análise em linhas gerais do DBC (2009), para além de apontar as dissonâncias desta obra, conforme os pilares teóricos da Lexicografia e Metalexicografia tem como intento colaborar, ainda que com uma pequena parcela, para a ampliação do trabalho lexicográfico na esfera da variação diatópica, que, segundo Isquerdo (2004), carece de espaço e investigação melhores sistematizados no âmbito dos estudos linguísticos. 


\section{Title: Microstructure's Aspects Of The "Dicionário Do Brasil Central - Subsídios À Filolgia" (2009): Description And Analysis}

\section{Abstract}

In this work we made a general analysis of the microstructure of the "Dicionário do Brasil Central - subsídios à Filologia”, by Waldomiro Bariani Ortêncio (2009), second edition, the electronic version. We presented lexicographyc's panorama work, that broaching since the composition of its reference corpus, the lexical proposal, the typological classification, number of entries and definitions recorded information that we consider necessary for a study of metalexicográfico content, even if our focus is the microstructural organization of the dictionary. Thus, we adopt a theoretical-methodological approach, the main theoretical contribution in respect of the specialized literature in the field of (Meta) lexicography, as Biderman (1984; 2001), Welker (2004), Haensch (1982), Isquerdo (2004; 2007) among other authors, simultaneous observation of the "Dicionário do Brasil Central - subsídios à Filologia" henceforth DBC (2009), essentially the electronic version. It is noteworthy that at times resorted to print the title of clarifying some doubts, because some reports that contained in the sections "Presentation" and "Introduction to the first edition," appearing in the dictionary only in the latter mode. With this study, we aimed to contribute to the expansion of lexicographical work in the sphere of diatopical variation.

Keywords: Microstructure; DBC (2009); Partial dictionary. 


\section{REFERÊNCIAS}

BIDERMAN, Maria Tereza Camargo. Lexema e lexia. Lexias simples e complexas. In:

Teoria Lingüística: teoria lexical e lingǘstica computacional. São Paulo: Martins Fontes, 2001. p. 169-178.

Os dicionários na contemporaneidade: arquiteturas, métodos e técnicas. In: OLIVEIRA, Ana Maria Pinto Pires de; ISQUERDO, Aparecida. Negri. (Orgs.). As ciências do léxico: lexicologia, lexicografia, terminologia. Campo Grande: EDUFMS, 2001. p. 131-144.

. A ciência da Lexicografia. Alfa. São Paulo, 28 (supl.), n.42, p. 1 -26, 1984b.

. 0 Dicionário Padrão da Língua. Alfa. São Paulo, 28 (supl.), n.42, p. 27-43, 1984b.

. Conceito de linguístico de palaura. In: BASÍllO, Margarida. A delimitação de unidades lexicais. Petrópolis: Vozes, 1999, p.81-97.

CARVALHINHOS, Patríicia; HENRIQUES, Claudio Cezar. Quais os critérios deveriam orientar os lexicógrafos na inserção de antropônimos e topônimos em dicionários gerais? In: XATARA, Cláudia; BEVILACQUA, Cleci Regina; HUMBLÉ, Philippe René Marie (Org.). Dicionários na teoria e na prática: como e para quem são feitos. São Paulo: Parábola Editorial, 2011, p. 79-86.

FRUBEL, Auri Claudionei Matos; ISQUERDO, Aparecida Negri. Vocabulário do falar sul-mato-grossense: aspectos lexicográficos e socioculturais. In: ISQUERDO, Aparecida Negri; KRIEGER, Maria da Graça, (Org.). As ciências do léxico: lexicologia, lexicografia, terminologia. Campo Grande - MS: EDUFMS, 2004. p. 153-166.

GLENK, Eva Maria Ferreira. Quais os critérios deveriam orientar os lexicógrafos na inserção da fraseologia popular (gíria, palaviões, idiomatismos etc.) em dicionários gerais? In: XATARA, Cláudia; BEVILACQUA, Cleci Regina; HUMBLÉ, Philippe René Marie (Org.). Dicionários na teoria e na prática: como e para quem são feitos. São Paulo: Parábola Editorial, 2011, p. 79-86.

HAENSCH, Günther. Tipologia de las obras lexicográficas. In: HAENSCH, Günther et al.(Org.). La Lexicografía - de la lingǘstica teórica a la lexicografia práctica.Madrid: Editorial Gredos, 1982. p. 95-187.

HOUAISS, Antônio; VILLAR, Mauro de Salles. Dicionário Houaiss da Língua Portuguesa. Rio de Janeiro: Objetiva, 2007.

ISQUERDO, Aparecida Negri. A propósito de dicionários de regionalismos do português do Brasil. In: ALVES, leda Maria; ISQUERDO, Aparecida Negri, (Org.) As ciências do léxico: lexicologia, lexicografia, terminologia. Campo Grande: EDUFMS; São Paulo: Humanitas, 2007. p. 283-293.

KRIEGER, Maria da Graça. Lexicografia: o léxico no dicionário. In. SEABRA, Maria Cândida Trindade Costa de. (Org.). 0 léxico em estudo. Belo Horizonte: Faculdade de Letras da UFMG, 2006, p.158-171.

MIRANDA, Félix Bugeño. 0 que é macroestrutura no dicionário de língua? In: ALVES, Ieda Maria; ISQUERDO, Aparecida Negri (Org.) As ciências do léxico: lexicologia, lexicografia, terminologia. Campo Grande: EDUFMS; São Paulo: Humanitas, 2007, p. 261-272.

MURAKAWA, Clotilde de Almeida Azevedo. Modelos de verbetes em dicionários clássicos da língua portuguesa. In: ALVES, leda Maria; ISQUERDO, Aparecida Negri, (Org.) As ciências do léxico: lexicologia, lexicografia, terminologia. Campo Grande: EDUFMS; São Paulo: Humanitas, 2007. p. 235-245.

ORTÊNCIO, Bariani. Dicionário do Brasil Central - subsídios à Filologia. 2. ed. rev. e ampl. Goiânia: Kelps, 2009. REY-DEBOVE, Josette. Léxico e dicionário. Trad. Clóvis Barleta de Morais. Alfa, v. 28 (supl.), São Paulo, p. 45-69, 1984. 
SILVA, Maria Cristina Parreira da. Para uma tipologia geral de obras lexicográficas. In: ALVES, leda Maria; ISQUERDO, Aparecida Negri (Org.) As ciências do léxico: lexicologia, lexicografia, terminologia. Campo Grande: EDUFMS; São Paulo: Humanitas, 2007. p. 193-208. TAGNIN, Stella. Como os lexicógrafos poderiam descrever satisfatoriamente s colocações? In: XATARA, Cláudia; BEVILACQUA, Cleci Regina; HUMBLÉ, Philippe René Marie (Org.). Dicionários na teoria e na prática: como e para quem são feitos. São Paulo: Parábola Editorial, 2011. 